\title{
Associations between characteristics of the home food environment and fruit and vegetable intake in preschool children: A cross-sectional study
}

Rebecca Wyse ${ }^{1,2^{*}}$, Elizabeth Campbell ${ }^{1,2,3}$, Nicole Nathan ${ }^{1,2,3}$ and Luke Wolfenden ${ }^{1,2}$

\begin{abstract}
Background: Early childhood is critical to the development of lifelong food habits. Given the high proportion of children with inadequate fruit and vegetable consumption, identification of modifiable factors associated with higher consumption may be useful in developing interventions to address this public health issue. This study aimed to identify the characteristics of the home food environment that are associated with higher fruit and vegetable consumption in a sample of Australian preschool children.

Methods: A cross-sectional telephone survey was conducted with 396 parents of 3 to 5 year-old children attending 30 preschools within the Hunter region, New South Wales, Australia. Children's fruit and vegetable consumption was measured using a valid and reliable subscale from the Children's Dietary Questionnaire. Associations were investigated between children's fruit and vegetable intake and characteristics of the home food environment including parental role-modeling, parental providing behaviour, fruit and vegetable availability, fruit and vegetable accessibility, pressure to eat, family eating policies and family mealtime practices. Characteristics of the home food environment that showed evidence of an association with children's fruit and vegetable consumption in simple regression models were entered into a backwards stepwise multiple regression analysis. The multiple regression analysis used generalised linear mixed models, controlled for parental education, household income and child gender, and was adjusted for the correlation between children's fruit and vegetable consumption within a preschool.
\end{abstract}

Results: The multiple regression analysis found positive associations between children's fruit and vegetable consumption and parental fruit and vegetable intake $(p=0.005)$, fruit and vegetable availability $(p=0.006)$ and accessibility $(p=0.012)$, the number of occasions each day that parents provided their child with fruit and vegetables $(p<0.001)$, and allowing children to eat only at set meal times all or most of the time $(p=0.006)$. Combined, these characteristics of the home food environment accounted for $48 \%$ of the variation in the child's fruit and vegetable score.

Conclusions: This study identified a range of modifiable characteristics within the home food environment that are associated with fruit and vegetable consumption among preschool children. Such characteristics could be considered potential targets for interventions to promote intake among children of this age.

\section{Background}

Adequate consumption of fruit and vegetables provides children with essential nutrients for healthy growth and development [1] and may displace the consumption of energy-dense, nutrient-poor foods associated with

\footnotetext{
* Correspondence: Rebecca.Wyse@hnehealth.nsw.gov.au

'Faculty of Health, School of Medicine and Public Health, University of

Newcastle, c/o Locked Bag 10, Wallsend, NSW 2287, Australia

Full list of author information is available at the end of the article
}

childhood overweight and obesity [2-6]. Given that childhood diet is a significant determinant of adult diet [7] and higher fruit and vegetable consumption in childhood is associated with decreased risk of adult chronic disease $[8,9]$, the benefits of adequate childhood fruit and vegetable consumption appear to extend throughout the lifespan. Despite this, internationally, a high proportion of children have inadequate fruit and vegetable intake $[10,11]$. Identifying factors associated with higher

\section{() Biomed Central}


childhood fruit and vegetable consumption may assist in the development of interventions to address this public health issue.

Many factors influence the foods that children eat: the demographic and socio-economic characteristics of their families $[10,11]$; their individual preferences and genetic predispositions [12,13]; psychosocial factors [14]; and characteristics of their environment $[15,16]$. Given the amount of time children spend in the home, this environment represents a potentially promising setting in which to improve young children's fruit and vegetable consumption. Rosenkranz's ecological model of the home food environment hypothesises that child diet in this setting is influenced by three domains: built and natural environments; political and economic environments; and socio-cultural environments [17]. Of these, those most proximal to a child's life, such as home accessibility and availability of foods (built and natural environments) and parental diet, parenting practices and rules, and family eating patterns (socio-cultural environments) may be most amenable to intervention. As such, research investigating associations between these characteristics of the home environment and children's fruit and vegetable consumption is warranted.

Studies of school-aged children have found parental fruit and vegetable intake and the accessibility and availability of fruit and vegetables in the home $[12,15,16]$ to be consistently associated with children's consumption. However, research involving children of preschool age (children aged 3 to 5 years [18]) is limited. For example, a 2007 systematic review that included environmental correlates of children's fruit and vegetable intake identified just three studies involving children of preschoolage, compared with 30 studies involving children aged 5-18 years [16], while a more recent systematic review only included studies of children aged 6 years and older [15]. The factors influencing dietary habits in early childhood be may distinct from those affecting schoolaged children, due to preschoolers' earlier developmental stage and greater dependence on their family [15]. The few studies that have investigated associations between such factors and fruit and vegetable consumption in preschool children found positive associations with parental fruit and vegetable intake [19-21] and parental role-modeling [22]; and negative associations with eating in front of the television [23] and parental pressure to eat $[21,23]$. However, only a minority of these studies, have used both a comprehensive or validated assessment of child fruit and vegetable consumption and multivariate analyses to isolate the effect of individual variables and control for the influence of socio-demographic characteristics [20,21]. As such, this study sought to address these limitations, and identify characteristics of the home food environment associated with fruit and vegetable consumption in a sample of Australian preschool children.

\section{Methods \\ Design}

A cross-sectional survey of parents of preschool-aged children was conducted via Computer Assisted Telephone Interview (CATI).

\section{Ethical approval}

The data for the present study forms the baseline dataset for a cluster randomised controlled trial of a telephone-based intervention to increase fruit and vegetable consumption in preschool children [24]. Ethical approval for the broader trial was obtained from the Human Research Ethics Committees of the University of Newcastle (Ref No. H-2008-0410) and the Hunter New England Area Health Service (Ref No. 08/10/15/5.09).

\section{Sample}

Study participants were parents of 3 to 5 year-old children attending non-government preschools within the Hunter region of New South Wales, Australia. Almost 90\% of preschools within New South Wales are either privately run or run by the community [25]. All participants had previously volunteered to participate in a telephone-based randomised controlled trial of a fruit and vegetable intervention [24]. Preschools were ineligible if they provided children with meals, if they catered exclusively for children with special needs, were government preschools (as the conduct of this research was not approved in these institutions) or if they had participated in child healthy eating research projects within the prior six months. Parents were eligible if they resided with their preschool child for at least 4 days per week and were responsible for their child's meals and snacks at least half of the time. If children had dietary restrictions that were incompatible with the Australian Dietary Guidelines for fruit and vegetable consumption (as determined by an Accrediting Practicing Dietitian), their parents were deemed ineligible.

\section{Recruitment}

Recruitment procedures are described in detail elsewhere [24] and are based on a systematic review identifying effective strategies for recruiting parents for study participation through schools [26]. Briefly, all eligible preschools within the study area were invited to participate. At consenting preschools, a research assistant distributed study information and consent forms to parents as they dropped off or picked up their child. Parents indicated their consent by ticking a box on the consent form and returning it to a drop box at the preschool. Recruitment of preschools began in February 2010 and 
recruitment of parents began in March 2010 and was conducted over a 6-month period. The consent form contained questions about the parent's residential suburb, the child's age, gender, and usual fruit and vegetable consumption (average number of serves per day). In order to assess bias due to selective non-participation, parents who did not wish to participate in the study were encouraged to also complete a consent form with this information and return it to the preschool.

\section{Data Collection}

Consenting parents were contacted to complete a telephone survey via CATI delivered by telephone interviewers experienced in conducting health-related interviews. The survey was conducted from April to October 2010. Parents were instructed to answer with respect to their preschool-aged child. If they had more than one child aged 3 to 5 years, they were instructed to select the child who would have the next birthday.

\section{Measures}

\section{Participant characteristics}

The survey included items to assess the socio-demographic characteristics of parents and children. Parents were asked their age, gender, highest level of education and annual household income and whether they identified as Aboriginal and/or Torres Strait Islander, and were asked to report their child's date of birth and gender. Items were sourced from population health surveys [27]. Parents were also asked the number of days per week that they resided with their child, and how often they were responsible for providing their child with meals and snacks (always, most of the time, half of the time, seldom, never).

\section{Children's fruit and vegetable intake}

Participants also completed the fruit and vegetable subscale of the Children's Dietary Questionnaire (CDQ) [28]. This subscale requires parents to report the variety and frequency of fruit and vegetables consumed by their child over the past 24 hours and past 7 days. This tool includes potatoes and sweet potatoes in the assessment of vegetable consumption, but parents are specifically instructed not to include hot chips. Fruit and vegetable juices are excluded from most (3 out of 4) questions assessing the frequency and variety of fruit intake, with the exception of the number of occasions of fruit or vegetable consumption over the past 24 hours. The subscale score ranges from 0 to 28 and a score of 14 or more suggests that the child has intake patterns consistent with fruit and vegetable dietary guidelines [28]. Changes on this score could arise from a range of possible changes to children's fruit and vegetable consumption patterns, for example, a one-point increase could result from eating an additional type of fruit or vegetable, or eating fruit or vegetable at an additional occasion in the previous 24 hours. This subscale has been established as reliable in comparable samples of preschoolers (intracorrelation coefficient $=0.75$ ), and has been established as valid against a 7-day dietary checklist in a sample of school-aged children (Spearman's correlation coefficient $=0.58$ ) [28].

\section{Characteristics of the home food environment}

Characteristics of the home food environment were assessed within seven domains: Parental role-modeling of fruit and vegetable consumption, pressure to eat, parental provision of fruit and vegetables, fruit and vegetable availability, fruit and vegetable accessibility, mealtime practices and family eating policies. Where possible, items were taken from existing validated measures of the home food environment including The Healthy Home Survey [29], The Child Feeding Questionnaire [30] and The National Nutrition Survey [31]. Where known, the reliability and validity of items are provided alongside each item. Study items with unknown psychometric properties are also identified.

a) Parental role-modeling of fruit and vegetable consumption Items from the National Nutrition Survey were included to assess the average number of serves of fruit and vegetables consumed each day by parents [31]. Answers to these questions have been positively associated with objective biomarkers of fruit and vegetable intake including $\alpha$-carotene, $\beta$-carotene, $\beta$-cryptoxanthin, lutein/zeaxanthin and red-cell folate [32]. A lack of existing role-modeling items that were specific to fruit and vegetable consumption, quantitative, and targeted at parents of preschool children led the study team to develop two items to assess this. Specifically, parents were asked separate questions regarding the number of times they had consumed fruits, and the number of times they had consumed vegetables, in front of their child on the previous day. The validity of these items is unknown.

b) Pressure to eat The 'Pressure to Eat' subscale from Birch's Child Feeding Questionnaire was included to measure the extent to which parents try to control the amount and type of food eaten by their child [30]. Scores range from 1 to 5 and a higher score indicates more pressure. The four-item scale has been shown to be internally consistent (Cronbach's alpha $=0.70$ ) and reliability estimates for the four items of this subscale are 0.19-0.52 [30].

c) Parental provision of fruit and vegetables As no items or scales could be identified that measured the extent to which parents provided their children with fruit and vegetables, two questions were developed specifically for this study, and as such their psychometric properties are unknown. Separate questions were asked regarding the number of occasions on the previous day 
that the parent provided the child with fruits and with vegetables.

d) Availability of fruit and vegetables in the home As no appropriate measure of home fruit and vegetable availability that was brief, suitable for telephone data collection, and appropriate for use within an Australian sample could be sourced, to assess this, parents were read a list of 19 commonly consumed fruits and 24 commonly consumed vegetables from the Children's Dietary Questionnaire. Fruit and vegetables could be available in any form: fresh, tinned, frozen or dried. Parents were asked to identify those that they had in their home at that time and the number of varieties of fruits and vegetables were then summed. The validity and reliability of this item are unknown.

e) Accessibility of fruit and vegetables in the home Accessibility was assessed by asking whether fruit and vegetables in the home were stored in a form that facilitated their consumption, for example, washed and chopped. The vegetable item was taken from the Healthy Home Survey (item reliability, kappa $=0.57$, item validity, kappa $=0.43$ ) [29]. The reliability and validity of the Healthy Home survey items were established in a study of 85 American families with 3 to 8 year-old children by having $50 \%$ of the sample re-do the survey one week after the first administration, and by a home-visit to $95 \%$ of participants [29]. As there was no equivalent item for fruit, this was adapted from the vegetable item, specifically: Do you have any ready to eat fresh fruit on a shelf in the refrigerator or on the kitchen counter now, for example, fruit you have washed or chopped to make ready to eat, like bunches of grapes, berries, or oranges?

f) Mealtime practices The extent to which the family was adopting mealtime practices that encouraged child fruit and vegetable consumption was measured using items from the Healthy Home Survey. Items taken from this survey included the location where most meals are eaten, the number of days per week the family sits at a table to eat dinner together, and the number of days per week the child eats dinner in front of the television (Item reliability kappa $=0.73-0.80$ ) [29].

g) Family eating policies Questions from the Healthy Home Survey were also included to assess the extent to which parents adopted eating policies that encouraged fruit and vegetable consumption. On a five-point likert scale ('all of the time' to 'never') parents recalled the frequency with which they did each of the following: ask their child to eat everything on their plate at dinner; restrict dessert if their child does not eat the food on their plate at dinner; reward their child with desserts, snacks or confectionary if they finish their dinner; allow their child to eat only at set meal times; and allow their child to help him/herself to snacks when at home (Item reliability kappa $=0.40-0.75)$ [29].

\section{Analysis}

All analyses were conducted using SAS 9.2 (SAS Institute Inc., Cary, NC, USA). Descriptive statistics were used to describe the sample. Where quantitative items were used to collect information about environmental characteristics relating to fruits and vegetables separately, these totals were summed to form a single variable, for example, parental intake, parental rolemodeling, fruit and vegetable availability within the home and parental providing behaviour. Similarly, the two accessibility items were combined into a single item indicating whether both fruit and vegetables were stored in a ready-to-eat format or whether fruit, or vegetables, or both fruit and vegetables were not stored in this way. Consistent with previous research on Australian parents of preschoolers [33] parental education was dichotomised into 'university educated' and 'other', and annual household income was split into less than $\$ 100,000$ and $\$ 100,000$ or more. Categorical variables used to assess eating policies were recoded dichotomously, whereby "all of the time" and "most of the time" responses were combined to reflect consistent adoption of these policies, and "some of the time", "rarely" and "never" were also combined. Non-normal continuous variables (days per week the family eats dinner together at a table, days per week the child eats dinner in front of the television) were treated as dichotomous categorical variables. The cut points were set at the frequencies with which the highest levels of children's fruit and vegetable consumption have previously been associated [34-37]. Therefore the number of days per week the family eats dinner together at a table was split into 7 days and less than 7 days, and the number of days per week the child eats dinner in front of the television was split into 0 days and 1 or more days. Similarly, the location where most meals were eaten was recoded into 'table' and 'other' [38].

A series of simple regression models were run investigating the association between each characteristic of the home food environment and children's fruit and vegetable consumption. Simple regression models also investigated socio-demographic characteristics for which associations with children's fruit or vegetable intake had previously been found; parental education [10], household income [39], child gender [19] and child age [19]. As numerous simple regression models were being tested, a Bonferroni adjustment was applied to the pvalue (0.003) to account for the increased likelihood of type one error [40]. As evidence suggests fruit and vegetable consumption varies between children attending 
different childcare centres [41], all regression analyses used generalised linear mixed models (Proc Mixed) with a random intercept term to adjust for the correlation of measurements within a preschool.

A screening criterion of $\mathrm{p}<0.25$ was adopted to determine which variables would be included in the multiple regression analysis. A criterion of $\mathrm{p}<0.25$ was used as evidence suggests that adopting the traditional threshold $(\mathrm{p}<0.05)$ can exclude variables of known importance $[42,43]$. A backwards stepwise approach was used to determine the final multiple regression model with the least significant characteristic of the home food environment removed and the analysis re-run until only significant variables remained. Socio-demographic variables that satisfied the screening criterion $(\mathrm{p}<0.25)$ were controlled for in the multiple regression model (i.e. they were included in the stepwise process and retained in the final model).

\section{Results}

The sample consisted of 396 parents, recruited from 30 preschools across the Hunter region. Of the 57 preschools within the sampling frame, 30 consented, 19 were ineligible, seven refused to participate and one could not be contacted. Children from approximately 2,200 families attended the 30 preschools, and 417 parents consented to participate, with a further 178 returning a form indicating that they did not consent to participate. Of the consenters, ten refused to participate when contacted to complete the survey, six were ineligible and five could not be contacted, resulting in a total of 396 parents providing data for the analysis. The study sample and the characteristics of their home food environments are described in Table 1.

There were no significant differences between participants and those non-consenters who returned a form with respect to child age, gender, daily serves of fruit or vegetables, or level of disadvantage based on residential postcode [44]. However, only a small proportion (approximately 10\%) of the families who did not participate returned a completed consent form. In comparison with a regionally representative sample of children aged 2 to 4 years, a similar proportion of children in this study consumed at least one serve of fruit per day, but a higher proportion of children in the study consumed at least two serves of vegetables per day [45].

Most parents (99\%) lived with their child 7 days a week and most (74\%) reported that they were 'always' responsible for their child's meals and snacks, with $22 \%$ and $5 \%$ reporting they were responsible 'most of the time' and 'half of the time' respectively. Parents consumed an average of five serves of fruit and vegetables each day and consumption levels approximated that of female adults of a similar age within the region [45]. On average, parents ate fruit and vegetables in front of their children more than two occasions per day and provided their children with fruit and vegetables more than three times a day. While, on average, households had almost 22 different types of fruit and vegetables available in the house, fewer than half of those households (39\%) kept both fruit and vegetables in a ready-to-eat, accessible format. On average, families ate together at a table 5.6 days a week (with $57 \%$ eating together 7 days a week) and children ate dinner in front of the television on an average of 2.2 days a week (with $47 \%$ not doing this at all, i.e. 0 days per week). The majority of families (87\%) ate most meals at a table. Although $59 \%$ of parents indicated that they would restrict dessert 'most' or 'all of the time' when their child did not eat their dinner, $29 \%$ rewarded their child with dessert for finishing dinner. Only $4 \%$ of parents allowed their child to access snacks themselves.

The mean score for the fruit and vegetable subscale for children within the study was 14.8 (sd 4.6). Table 2 displays the strength of the associations between children's fruit and vegetable score and characteristics of the home food environment and socio-demographic characteristics in simple and multiple regression models.

Simple regression analysis found statistically significant positive associations ( $p<0.003$ ) between children's fruit and vegetable consumption and the following factors: parental fruit and vegetable intake; occasions per day where parents role-model fruit and vegetable consumption; provision of fruit or vegetables to children; variety of fruit and vegetables available in the home; keeping fruit and vegetables in a ready-to-eat format (e. g. washed and chopped); and only allowing children to eat at set meal times.

Twelve characteristics of the home food environment had a p-value less than 0.25 in the simple regression models and were entered into the backward stepwise regression along with parental education, household income and child gender. The assumptions of multiple regression were tested and found to be acceptable. The regression coefficients, 95\% confidence intervals and pvalues for the five significant variables $(p<0.05)$ that were retained in the final regression model are shown in the final two columns of Table 2 .

Multiple regression analysis indicated that higher fruit and vegetable consumption in children was significantly associated with: higher fruit and vegetable intake in parents, more frequent provision of fruit and vegetables to children throughout the day, having a wider variety of fruits and vegetables available in the home, having fruit and vegetables stored in a ready-to-eat format, and generally only allowing children to eat at set mealtimes. These variables remained significant despite controlling for parental education, household income and the 
Table 1 Parent, child and home food environment characteristics of the $\mathbf{3 9 6}$ study participants

\begin{tabular}{|c|c|}
\hline Sample characteristics & Mean $(\mathrm{SD}) / \%$ \\
\hline \multicolumn{2}{|l|}{ Parent characteristics } \\
\hline Mean age (SD) - years & $35.5(5.3)$ \\
\hline Gender - female & $96 \%$ \\
\hline Aboriginal and/or Torres Strait Islander & $2 \%$ \\
\hline \multicolumn{2}{|l|}{ Highest educational level } \\
\hline Years 7-9 & $2 \%$ \\
\hline Years 10 & $11 \%$ \\
\hline Year 11-12 & $10 \%$ \\
\hline TAFE (Technical and Further Education) & $30 \%$ \\
\hline University & $47 \%$ \\
\hline \multicolumn{2}{|l|}{ Annual household income* } \\
\hline$<\$ 20,000$ & $4 \%$ \\
\hline$\$ 20,000-\$ 39,999$ & $9 \%$ \\
\hline$\$ 40,000-\$ 59,999$ & $11 \%$ \\
\hline$\$ 60,000-\$ 79,999$ & $15 \%$ \\
\hline$\$ 80,000-\$ 99,999$ & $19 \%$ \\
\hline$\$ 100,000$ & $41 \%$ \\
\hline \multicolumn{2}{|l|}{ Child characteristics } \\
\hline Mean age (SD) - years & $4.3(0.6)$ \\
\hline Gender - female & $49 \%$ \\
\hline Mean daily serves of fruit $(S D)^{\#}$ & $2.3(1.0)$ \\
\hline Mean daily serves of vegetables (SD) ${ }^{\#}$ & $2.1(1.1)$ \\
\hline \multicolumn{2}{|l|}{ Home food environment characteristics } \\
\hline \multicolumn{2}{|l|}{ Parental role-modeling } \\
\hline Daily serves of fruit \& vegetables & $5.0(1.8)$ \\
\hline Occasions/day modeled fruit \& vegetable consumption & $2.3(1.4)$ \\
\hline \multicolumn{2}{|l|}{ Pressure to eat } \\
\hline Pressure to eat & $3.1(0.7)$ \\
\hline \multicolumn{2}{|l|}{ Parent providing behaviour } \\
\hline Times/day parent provides fruit \& vegetables & $3.2(1.3)$ \\
\hline \multicolumn{2}{|l|}{ Fruit and vegetable availability } \\
\hline Different varieties of fruit \& vegetables in home & $21.7(4.8)$ \\
\hline \multicolumn{2}{|l|}{ Fruit and vegetable accessibility } \\
\hline Fruit and vegetables kept in ready to eat format (\% yes) & $39 \%$ \\
\hline \multicolumn{2}{|l|}{ Mealtime practices } \\
\hline Always eat together as a family (7 nights per week) & $57 \%$ \\
\hline Never eat in front of TV (0 nights per week) & $47 \%$ \\
\hline Family eats most meals at table/bench (\% who all or most of the time) & $87 \%$ \\
\hline \multicolumn{2}{|l|}{ Family eating policies (\% who all or most of the time ...) } \\
\hline Ask child to eat everything on their plate at dinner & $50 \%$ \\
\hline Restrict dessert if child does not eat dinner & $59 \%$ \\
\hline Reward with dessert if child finishes dinner & $29 \%$ \\
\hline Only allow child to eat at set mealtimes & $39 \%$ \\
\hline Allow child to help him/herself to snacks & $4 \%$ \\
\hline
\end{tabular}

\footnotetext{
* Excluding $n=17$ (don't know or refused)
}

\# Information collected from consent form 
Table 2 Associations between CDQ score and characteristics of the home food environment: simple and multiple regression

\begin{tabular}{|c|c|c|c|c|}
\hline & Simple Regression & & Multiple Regression & \\
\hline $\begin{array}{c}\text { Characteristic } \\
(\mathrm{n}=396)\end{array}$ & $\begin{array}{l}\text { Regression co-efficient }(95 \% \\
\mathrm{Cl})\end{array}$ & $\begin{array}{c}\mathrm{p}- \\
\text { value }\end{array}$ & $\begin{array}{l}\text { Regression co-efficient (95\% } \\
\mathrm{Cl} \text { ) }\end{array}$ & $\begin{array}{c}\mathrm{p}- \\
\text { value }\end{array}$ \\
\hline \multicolumn{5}{|l|}{ Parental role-modeling } \\
\hline Daily serves of fruit \& vegetables (F\&V) & $0.87(0.64-1.11)$ & $<0.001$ & $0.30(0.09-0.50)$ & 0.005 \\
\hline Occasions/day modeled F\&V consumption & $1.09(0.78-1.40)$ & $<0.001$ & & \\
\hline \multicolumn{5}{|l|}{ Pressure to eat } \\
\hline Pressure to eat & $-0.78(-1.40--0.17)$ & 0.012 & & \\
\hline \multicolumn{5}{|l|}{ Parent providing behaviour } \\
\hline Times/day parent provides F\&V & $2.22(1.96-2.49)$ & $<0.001$ & $1.80(1.53-2.09)$ & $<0.001$ \\
\hline \multicolumn{5}{|l|}{ Fruit and vegetable availability } \\
\hline Different varieties of F\&V in home & $0.34(0.25-0.43)$ & $<0.001$ & $0.12(0.03-0.20)$ & 0.006 \\
\hline \multicolumn{5}{|l|}{ Fruit and vegetable accessibility* } \\
\hline F\&V kept in ready to eat format (Yes) & $1.80(0.87-2.73)$ & $<0.001$ & $0.90(0.20-1.60)$ & 0.012 \\
\hline \multicolumn{5}{|l|}{ Mealtime practices* } \\
\hline Always eat together as a family ( 7 nights per week) & $0.90(-0.02-1.82)$ & 0.055 & & \\
\hline Never eat dinner in front of TV (0 nights per week) & $0.87(-0.04-1.79)$ & 0.061 & & \\
\hline $\begin{array}{l}\text { Family eats most meals at table/bench (All or most of the } \\
\qquad \text { time) }\end{array}$ & $0.48(-0.86-1.82)$ & 0.480 & & \\
\hline \multicolumn{5}{|l|}{ Family eating policies* } \\
\hline \multicolumn{5}{|l|}{ (\% who all of most of the time ...) } \\
\hline Ask child to eat everything on plate at dinner & $-0.05(-0.96-0.87)$ & 0.922 & & \\
\hline Restrict dessert if child does not eat dinner & $-0.68(-1.60-0.25)$ & 0.151 & & \\
\hline Reward with dessert if child finishes dinner & $-0.79(-1.79-0.21)$ & 0.121 & & \\
\hline Only allow child to eat at set mealtimes & $1.38(0.46-2.31)$ & 0.003 & $1.00(0.31-1.68)$ & 0.006 \\
\hline Allow child to help him/herself to snacks & $-1.59(-3.90-0.72)$ & 0.177 & & \\
\hline \multicolumn{5}{|l|}{ Socio-demographic characteristics ${ }^{\#}$} \\
\hline Parental education - University & $1.13(0.22-2.05)$ & 0.015 & & \\
\hline Annual household income $>\$ 100,000$ & $0.87(-0.05-1.79)$ & 0.065 & & \\
\hline Child gender & $0.64(-0.27-1.55)$ & 0.169 & & \\
\hline Child age & $-0.12(-0.87-0.64)$ & 0.765 & & \\
\hline
\end{tabular}

* Dichotomous characteristics

\# Parental education, household income and child gender were controlled for in the multivariate model but were not significant; $p=0.172, p=0.848, p=0.164$ respectively.

gender of the child. This model of the characteristics of the home food environments accounted for $48 \%$ of the variation in the child's fruit and vegetable score. The regression coefficients suggest that, all other factors held constant, each additional occasion that parents provide their children with fruit or vegetables throughout the day is associated with an average an increase in children's fruit and vegetable score of 1.80 points, and that ensuring that children generally only eat at set mealtimes is associated with an average increase of 1.00 points in the fruit and vegetable score. The coefficients of the remaining three significant variables within the model ranged from 0.12 to 0.90 .

\section{Discussion}

This study is one of only a handful of studies examining associations between characteristics of the home food environment and the fruit and vegetable consumption of preschool-aged children, and among the first to investigate these relationships through multiple regression analysis and with a reliable and valid measure of fruit and vegetable intake. The study found that greater fruit and vegetable consumption in children was positively associated with parent's own fruit and vegetable consumption; the frequency with which parents provide these foods to their child; the availability and accessibility of these foods in the home; and with maintaining set mealtimes. Such findings provide insights into factors that influence young children's vegetable and fruit intake.

The positive association between child and parent fruit and vegetable intake is supported by studies involving preschool-aged children [19-21] as well as older children and adolescents $[14,18,48,49]$ and supports previous recommendations that modification of parent diet be a 
key strategy for interventions targeting children's eating habits $[5,19,21,38,46]$. A lack of significant association between child fruit and vegetable intake and parental consumption of these foods in front of their children, however, suggests that the influence of parental rolemodeling is complex $[47,48]$. Further research investigating the mechanisms by which parental intake may influence child consumption may yield important insights for intervention.

A unique aspect of this study was the examination of parental provision of fruit and vegetables as a correlate of child consumption. Although the reported positive association is somewhat intuitive for children of this age, the finding accentuates the critical role that parents play in facilitating fruit and vegetable consumption through provision of these foods. Within the study sample at least, the findings also suggest that there is considerable scope to further improve child fruit and vegetable intake through encouraging more frequent provision. On average, parents provided fruit or vegetables to their child on 3.2 occasions per day, with dinner being the most prevalent occasion for serving vegetables, and morning tea the most prevalent occasion for serving fruit. Given that it is recommended that children of this age have three meals and two to three small snacks daily [49], introducing fruit and vegetables at additional occasions throughout the day, particularly the provision of vegetables for morning or afternoon teas, could represent an effective intervention strategy. Further, the findings of this, and other studies with older children $[50,51]$ demonstrate a greater likelihood for children to eat fruits and vegetable if they are stored at home in a ready-to-eat form. As preparation time is a commonly cited barrier to fruit and vegetable consumption [52,53], having ready-to-eat fruit and vegetables on hand may increase the likelihood of parents feeding their preschool child these foods rather than convenient, pre-packaged, snack foods. As only $39 \%$ of parents in this study reported storing fruit and vegetables in this way, strategies that make it easier for parents to purchase, prepare and store ready-to-eat fruits and vegetables are needed and likely to facilitate increased parent provision of these foods to their child.

These findings should be considered in the context of the study limitations. First, this data is cross-sectional, precluding conclusions regarding causality. Further research is warranted to determine if these associations are evident in longitudinal research, and if changes to such characteristics mediate the changes to child fruit and vegetable intake following intervention. Second, use of parent volunteers may have introduced selection-bias as study participants may not be representative of the broader population from which they were drawn. Compared to a random sample of 764 mothers of 2 to 5 year-olds in the broader study region, parents in this study were more educated ( $47 \%$ vs $36 \%$ with a university education) and from higher income households (41\% vs $20 \%$ earning over $\$ 100,000$ per year) [33] and their children had higher levels of vegetable consumption than a regionally representative sample of children aged 2 to 4 years [45]. The strength of the associations found in this study is therefore unknown among families from less advantaged backgrounds. Furthermore, most participants identified themselves as the parent that was primarily responsible for feeding their child, and only $4 \%$ of the participants were fathers, most likely due to fathers being less likely to drop children at childcare [54] and being less likely to have primary responsibility for food within the household [55]. This may restrict the generalisability of study findings to mothers, and the primary food provider, rather than parents more broadly. The inclusion of measures of the home food environment with unknown validity and reliability is a further limitation of this research and further research is required to develop and refine appropriate measures suitable for population-based investigation. Finally, this research examined the combined consumption of fruit and vegetables. The analyses did not allow for the identification of the relative associations of environmental characteristics with fruit and vegetable intake separately [56]. Future research should seek to address these limitations.

\section{Conclusions}

The study findings suggest that a range of factors within the home food environment appear to be associated with young children's fruit and vegetable intake. The final regression model which included parental intake and parental provision of fruit and vegetables to their children, the availability and accessibility of fruit and vegetables in the home and having set mealtimes accounted for almost half of the variation in children's fruit and vegetable consumption. Such results suggest that there are modifiable factors within the home environment that may be appropriate targets for future interventions aimed at increasing fruit and vegetable consumption in preschool-aged children to address this substantial public health problem.

\section{Acknowledgements}

This project was funded by a Cancer Institute New South Wales grant with author LW receiving salary support from this institution. In-kind support was provided by Hunter New England Population Health and infrastructure support was provided by The Hunter Medical Research Institute.

\section{Author details}

'Faculty of Health, School of Medicine and Public Health, University of Newcastle, c/o Locked Bag 10, Wallsend, NSW 2287, Australia. ${ }^{2}$ Hunter Medical Research Institute (HMRI), Newcastle, Australia. ${ }^{3}$ Hunter New England Population Health, Hunter New England Area Health Service, Newcastle, Australia. 


\section{Authors' contributions}

Author RW led the development of this manuscript. Authors RW, EC and LW determined the research design and the measures to be used. All authors decided upon the analyses conducted, and contributed to, read and approved the final version of this manuscript.

\section{Competing interests}

The authors declare that they have no competing interests.

Received: 15 August 2011 Accepted: 16 December 2011 Published: 16 December 2011

\section{References}

1. Smith A, Kellet $E$, Schmerlaib $Y$ : The Australian guide to healthy eating: Background information for nutrition educators. Canberra Commonwealth Department of Health and Family Services; 1998

2. Lin B, Morrison RM: Higher fruit consumption linked with lower body mass index. Food review 2002, 25(3):28-32.

3. Tohill BC: Dietary intake of fruit and vegetables and management of body weight. World Health Organization; 2005.

4. Wosje KS, Khoury PR, Claytor RP, Copeland KA, Hornung RW, Daniels SR, Kalkwarf HJ: Dietary patterns associated with fat and bone mass in young children. Am J Clin Nutr 2010, 92(2):294-303.

5. Epstein LH, Gordy CC, Raynor HA, Beddome M, Kilanowski CK, Paluch R: Increasing fruit and vegetable intake and decreasing fat and sugar intake in families at risk for childhood obesity. Obes Res 2001, 9(3):171-178.

6. NSW Centre for Public Health Nutrition: Report on the consumption of vegetables and fruit in NSW: 2003. State of Food and Nutrition in NSW Series. Sydney 2003

7. Mikkila V, Rasanen L, Raitakari OT, Pietinen P, Viikari J: Longitudinal changes in diet from childhood into adulthood with respect to risk of cardiovascular diseases: The Cardiovascular Risk in Young Finns Study. Eur J Clin Nutr 2004, 58(7):1038-1045.

8. Maynard M, Gunnell D, Emmett P, Frankel S, Davey Smith G: Fruit, vegetables, and antioxidants in childhood and risk of adult cancer: the Boyd Orr cohort. J Epidemiol Community Health 2003, 57(3):218-225.

9. Ness AR, Maynard M, Frankel S, Smith GD, Frobisher C, Leary SD, Emmett PM, Gunnell D: Diet in childhood and adult cardiovascular and all cause mortality: the Boyd Orr cohort. Heart 2005, 91(7):894-898,

10. Dubois L, Farmer A, Girard M, Burnier D, Porcherie M: Demographic and socio-economic factors related to food intake and adherence to nutritional recommendations in a cohort of pre-school children. Public Health Nutr 2011, 14(6):1096-1104.

11. Laitinen S, Rasanen L, Viikari J, Akerblom HK: Diet of Finnish Children in Relation to the Family's Socio-Economic Status. Scand J Soc Med 1995, 23(2):88-94.

12. Rasmussen M, Krolner R, Klepp Kl, Lytle L, Brug J, Bere E, Due P: Determinants of fruit and vegetable consumption among children and adolescents: a review of the literature. Part I: Quantitative studies. Int J Behav Nutr Phys Act 2006, 3:22

13. Birch LL: Development of food preferences. Annu Rev Nutr 1999, 19(1):41-62.

14. McClain AD, Chappuis C, Nguyen-Rodriguez ST, Yaroch AL, Spruijt-Metz D: Psychosocial correlates of eating behavior in children and adolescents: a review. Int J Behav Nutr Phys Act 2009, 6:54.

15. Pearson N, Biddle SJ, Gorely T: Family correlates of fruit and vegetable consumption in children and adolescents: a systematic review. Public Health Nutr 2009, 12(2):267-283.

16. van der Horst K, Oenema A, Ferreira I, Wendel-Vos W, Giskes K, van Lenthe F, Brug J: A systematic review of environmental correlates of obesity-related dietary behaviors in youth. Health Educ Res 2007, 22(2):203-226.

17. Rosenkranz RR, Dzewaltowski DA: Model of the home food environment pertaining to childhood obesity. Nutr Rev 2008, 66(3):123-140.

18. National Health and Medical Research Council: Dietary Guidelines for Children and Adolescents in Australia incorporating the Infant Feeding Guidelines for Health Workers. Commonwealth of Australia; 2003.

19. Cooke L, Wardle J, Gibson EL, Sapochnik M, Sheiham A, Lawson M: Demographic, familial and trait predictors of fruit and vegetable consumption by pre-school children. Public Health Nutr 2004, 7(2):295-302.
20. Vereecken CA, Keukelier E, Maes L: Influence of mother's educational level on food parenting practices and food habits of young children. Appetite 2004, 43(1):93-103.

21. Fisher JO, Mitchell DC, Smiciklas-Wright H, Birch LL: Parental influences on young girls' fruit and vegetable, micronutrient, and fat intakes. J Am Diet Assoc 2002, 102:58-64.

22. Sweetman C, McGowan L, Croker H, Cooke L: Characteristics of Family Mealtimes Affecting Children's Vegetable Consumption and Liking. J Am Diet Assoc 2011, 111(2):269-273.

23. Spurrier NJ, Magarey AA, Golley R, Curnow F, Sawyer MG: Relationships between the home environment and physical activity and dietary patterns of preschool children: a cross-sectional study. Int I Behav Nutr Phys Act 2008, 5:31.

24. Wyse RJ, Wolfenden L, Campbell E, Brennan L, Campbell KJ, Fletcher A, Bowman J, Heard TR, Wiggers J: A cluster randomised trial of a telephone-based intervention for parents to increase fruit and vegetable consumption in their 3- to 5-year-old children: study protocol. BMC Public Health 2010, 10:216.

25. Preschool education in Australia. [http://www.aph.gov.au/ About_Parliament/Parliamentary_Departments/Parliamentary_Library/pubs/ BN/0708/PreschoolEdAustralia].

26. Wolfenden L, Kypri K, Freund M, Hodder R: Obtaining active parental consent for school-based research: a guide for researchers. Aust N Z J Public Health 2009, 33(3):270-275.

27. Centre for Epidemiology and Research: 2008 Report on Adult Health from the New South Wales Population Health Survey. Sydney: NSW Department of Health; 2009.

28. Magarey A, Golley R, Spurrier N, Goodwin E, Ong F: Reliability and validity of the Children's Dietary Questionnaire; a new tool to measure children's dietary patterns. Int J Pediatr Obes 2009, 4(4):257-265.

29. Bryant MJ, Ward DS, Hales D, Vaughn A, Tabak RG, Stevens J: Reliability and validity of the Healthy Home Survey: A tool to measure factors within homes hypothesized to relate to overweight in children. Int J Behav Nutr Phys Act 2008, 5(1):23.

30. Birch LL, Johnson SL, Grimm-Thomas K, Orlet Fisher J: The Child Feeding Questionnaire (CFQ). Operational Definitions of Factors, Scoring, and Summing Instructions. PA: The Pennysylvania State University; 1998.

31. Australian Bureau of Statistics: National Nutrition Survey: Users' Guide (4801.0). Canberra: ABS; 1995

32. Coyne T, Ibiebele TI, McNaughton S, Rutishauser IHE, O'Dea K, Hodge AM, McClintock C, Findlay MG, Lee A: Evaluation of brief dietary questions to estimate vegetable and fruit consumption using serum carotenoids and red-cell folate. Public Health Nutr 2005, 8(3):298-308.

33. Wolfenden L, Hardy LL, Milat A, Bell C, Sutherland R, Wiggers J: Prevalence and socio-demographic associations of overweight and obesity among children attending childcare services in rural and regional New Wouth Wales Australia. Nutr Diet 2011, 68:15-20.

34. Gillman MW, Rifas-Shiman SL, Frazier AL, Rockett HR, Camargo CA, Field AE, Berkey CS, Colditz GA: Family dinner and diet quality among older children and adolescents. Arch Fam Med 2000, 9(3):235-240.

35. Neumark-Sztainer D, Hannan PJ, Story M, Croll J, Perry C: Family meal patterns: Associations with sociodemographic characteristics and improved dietary intake among adolescents. J Am Diet Assoc 2003, 103:317-322.

36. Coon KA, Goldberg J, Rogers BL, Tucker KL: Relationships between use of television during meals and children's food consumption patterns. Pediatrics 2001, 107(1):E7.

37. Matheson DM, Killen JD, Wang Y, Varady A, Robinson TN: Children's food consumption during television viewing. Am I Clin Nutr 2004, 79(6):1088-1094

38. Golan M, Fainaru M, Weizman A: Role of behaviour modification in the treatment of childhood obesity with the parents as the exclusive agents of change. Int J Obes Relat Metab Disord 1998, 22(12):1217-1224.

39. Crawford PB, Obarzanek E, Schreiber GB, Barrier P, Goldman S, Frederick MM, Sabry ZI: The Effects of Race, Household Income, and Parental Education on Nutrient Intakes of 9- and 10-Year-Old Girls. Ann Epidemiol 1995, 5(5):360-368.

40. Howell DC: Fundamental Statistics for the Behavioral Sciences. 4 edition Pacific Grove: Brooks/Cole; 1999.

41. Cockroft J, Durkin M, Masding C, Cade J: Fruit and vegetable intakes in a sample of pre-school children participating in the 'Five for All' project in Bradford. Public Health Nutr 2005, 8(7):861-869. 
42. Hosmer DW, Lemeshow S: Applied Logistic Regression New York: John Wiley \& Sons; 1989.

43. Bendel RB, Afifi AA: Comparison of Stopping Rules in Forward "Stepwise" Regression. J Amer Statistical Assoc 1977, 72:46-53.

44. Australian Bureau of Statistics: Census of Population and Housing: SocioEconomic Indexes for Areas (SEIFA) (2033.0.55.001). Canberra: ABS; 2006

45. Centre for Epidemiology and Research: New South Wales Population Health Survey 2009 (HOIST). NSW Department of Health; 2009.

46. Hart CN, Raynor HA, Jelalian E, Drotar D: The association of maternal food intake and infants' and toddlers' food intake. Child Care Health Dev 36(3):396-403.

47. Sutherland LA, Beavers DP, Kupper LL, Bernhardt AM, Heatherton T, Dalton MA: Like Parent, Like Child: Child Food and Beverage Choices During Role Playing. Arch Pediatr Adolesc Med 2008, 162(11):1063-1069.

48. Tibbs T, Haire-Joshu D, Schechtman KB, Brownson RC, Nanney MS, Houston C, Auslander W: The relationship between parental modeling, eating patterns, and dietary Intake among African-American parents. J Am Diet Assoc 2001, 101:535-541.

49. Kids and Healthy Snacking - They Go Together. [http://parentinged.msu. edu/Portals/0/docs/Kids\%20and\%20Healthy\%20Snacking.pdf].

50. Wind M, de Bourdeaudhuij I, te Velde SJ, Sandvik C, Due P, Klepp KI, Brug J: Correlates of fruit and vegetable consumption among 11-year-old Belgian-Flemish and Dutch schoolchildren. J Nutr Educ Behav 2006, 38(4):211-221.

51. Cullen KW, Baranowski T, Owens E, Marsh T, Rittenberry L, de Moor C: Availability, accessibility, and preferences for fruit, $100 \%$ fruit juice, and vegetables influence children's dietary behavior. Health Educ Behav 2003, 30(5):615-626.

52. Dwyer J, Needham L, Simpson JR, Heeney ES: Parents report intrapersonal, interpersonal, and environmental barriers to supporting healthy eating and physical activity among their preschoolers. Appl Physiol Nutr Metab 2008, 33(2):338-346.

53. Yeh MC, Ickes SB, Lowenstein LM, Shuval $K$, Ammerman AS, Farris $R$, Katz DL: Understanding barriers and facilitators of fruit and vegetable consumption among a diverse multi-ethnic population in the USA. Health Promot Int 2008, 23(1):42-51.

54. Raikes HH, Summers JA, Roggman LA: Father Involvement in Early Head Start Programs. Fathering: A Journal of Theory, Research, and Practice about Men as Fathers 2005, 3(1):29-58.

55. Harnack L, Story M, Martinson B, Neumark-Sztainer D, Stang J: Guess who's cooking? The role of men in meal planning, shopping, and preparation in US families. J Am Diet Assoc 1998, 98(9):995-1000.

56. Glasson C, Chapman K, James E: Fruit and vegetables should be targeted separately in health promotion programmes: differences in consumption levels, barriers, knowledge and stages of readiness for change. Public Health Nutr 2010, 14:694-701.

\section{Pre-publication history}

The pre-publication history for this paper can be accessed here: http://www.biomedcentral.com/1471-2458/11/938/prepub

\section{doi:10.1186/1471-2458-11-938}

Cite this article as: Wyse et al:: Associations between characteristics of the home food environment and fruit and vegetable intake in preschool children: A cross-sectional study. BMC Public Health 2011 11:938.

\section{Submit your next manuscript to BioMed Central and take full advantage of:}

- Convenient online submission

- Thorough peer review

- No space constraints or color figure charges

- Immediate publication on acceptance

- Inclusion in PubMed, CAS, Scopus and Google Scholar

- Research which is freely available for redistribution 